\title{
A Brief Review on Wireless Sensor Network
}

\author{
V. Navya $\mathrm{Sri}^{1}$, R. Dharani ${ }^{2}$, N. Thirupathi $\mathrm{Rao}^{3}$ \\ ${ }^{1,2,3}$ Department of Computer Science and Engineering, Vignan's Institute of \\ Information Technology (A), Visakhapatnam-530049, AP, India, \\ Inakkathiru@gmail.com
}

\begin{abstract}
Remote Sensor Networks (WSNs) assume a noteworthy part in reforming the world by its detecting innovation. WSNs have developed as that capable innovation which has various applications, for example, for example, military tasks, reconnaissance framework, Intelligent Transport Systems (ITS) and so forth. WSNs include different sensor hubs, which catches the information from the encompassing nearby observing the outer condition. A significant part of the examination work is centered on influencing the sensor to arrange working with least utilization of vitality, so it can make due for longer span. The essential worry toward sparing vitality has been because of the releasing of those batteries on which sensor hubs are worked. Notwithstanding that, WSNs are additionally abused for its security viewpoints with the goal that it can be utilized as a part of some classified segments like military combat zone. This paper presents the WSN in various angles like applications, steering and information gathering, security viewpoints and furthermore briefs about reenactment stage that can be utilized as a part of WSNs. This paper contributes in a manner about presenting the WSNs in various parts of its activity and mirroring its noteworthiness.
\end{abstract}

Keywords: Introduction to WSN, Routing, Simulation platform in WSN, security aspects in WSN, applications of WSN.

\section{Introduction}

Progression in remote correspondence has made conceivable the improvement of remote sensor systems containing gadgets called sensor hubs. Sensor hubs are low power, little size and shabby gadgets, fit for detecting, remote correspondence and calculation. When the sensors are conveyed in the system they design themselves and interface with each other for information gathering and in this way sending the information to the Base Station.

Article history:

Received (April 13, 2019), Review Result (July 13, 2019), Accepted (September 6, 2019) 


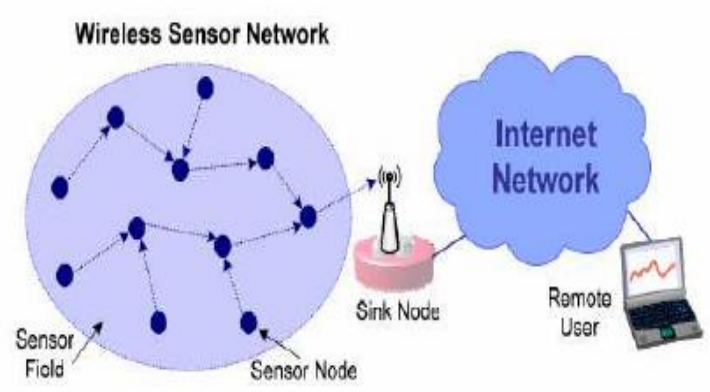

Figure.1 Architecture of Wireless sensor networks [9]

WSN can likewise be characterized as a system containing perhaps low-size and low multifaceted nature gadgets named as hubs which are fit for detecting the earth and conveying assembled data from the checked territory; the accumulated information can be transmitted specifically or through multi - jumps to sink, which would then be able to utilize it locally or is associated with different systems (e.g. web) through portal hubs [1][3][4]. The fundamental segments of sensor hub comprise of a detecting unit, a handling unit, a handset and a power unit as appeared in the Figure 2. Detecting unit detects the physical amount which is then changed into computerized one through ADC i.e. Simple to Digital converter. From there on processor is utilized for assist calculations and handset is utilized to transmit and get information from alternate hubs or from the Base Station. Power unit is the most noticeable unit in any sensor hub. Once the battery is depleted, it can't be swapped for unattended applications. Different units are application subordinate unit like Mobilizer, Power Generator and Location Finding System.

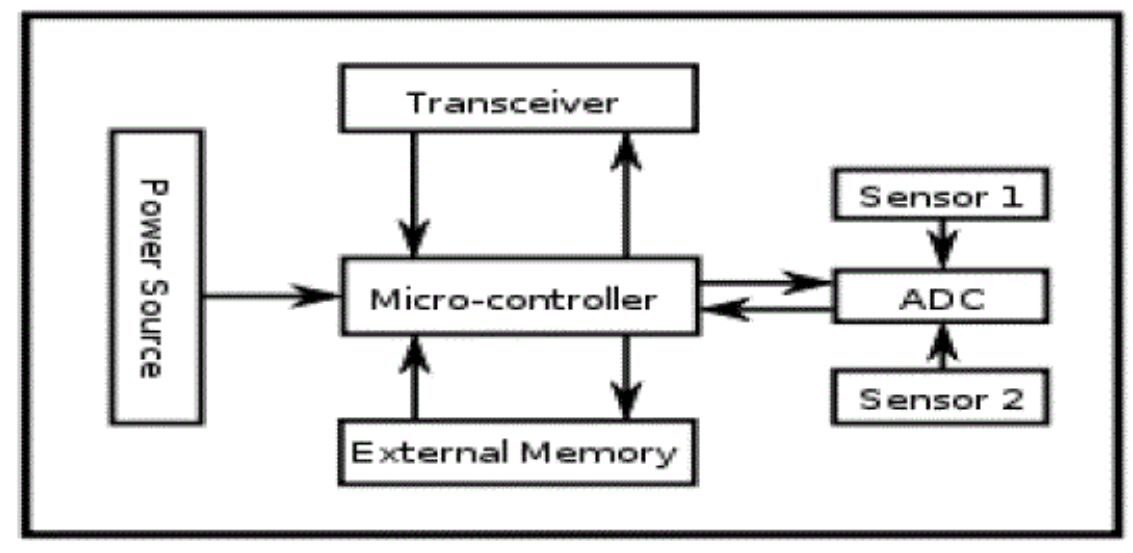

Figure.2 Components of a sensor network [10]

\section{CHALLENGES IN WSNS}

The development of wireless sensor networks are growing day to day as the technology is growing daily from a level to a higher levels. As the networks are growing in terms of operations and in terms of usage, the number of users being using these networks is growing day to day. As the utility is increasing several factors are needs to be considered and given importance for the analysis and working with these networks. At the same time, there will be 
several challenges to be faced while the networks are to be incorporated or to be used. Hence, in the current section a thought and light was given on the set of points and challenges to be considered for doing or dealing with these set of networks. Some of them are as follows [2][4][5].

\subsection{Hub organization:}

The set of nodes or group of node combines together in a common place or in a common junction is taken as hub and the organizing the nodes at these points plays a crucial role in the working of these networks. In wireless networks and sensor networks, the data collected from various set of nodes are collected to these hub points and this data to be processed further for various reasons. The data is to be updated from time to time such that to update the task more accurate and more sophisticated.

\subsection{Vitality utilization without losing precision:}

The utilization of the data collected from set of sensors and its units is very important and it should be processed from time to time. The data was collected continuously without any power loss or due to any other issues. As the data is being collected continuously, the users or the operators can expect the data more precisely and uninterrupted data can be uploaded. If any breaks or any further problems for collection of data or for the processing of data occur, the precision and accuracy of the data collection may not be the quality data as per the expectations from the user point of view[6].

\subsection{Information Supply to the Target Application:}

The collection of data and other items and processes related to these set of applications plays a key role in the working of wireless sensor networks. The sensor networks will have a group of sensor placed at various locations to collect the data from various locations with various set of data types too. Once the data is being collected from various sources, the data is processed and it is made ready for the other devices to accept the same data and to process it further. In general several units in an application or in other setoff applications or dependent on each other. The data required for one device may depend on the data to be shared by the other devices. Hence, the work in these networks is to collect the data through sensors, process it and further supply it to the set of other nodes in the different network or the same network such that to yield the good results from the same set of applications. Once the data is collected, processed then the required data to be supplied to the required network or the other devices in the network such that to operate normally and to produce the required results.

\subsection{Reporting Model:}

Data detecting and revealing in WSNs is subject to the application and the time criticality of the information announcing. Information detailing can be arranged as time-driven (constant), occasion driven, question driven, and half and half. The time-driven conveyance demonstrates is appropriate for applications that require intermittent information checking. In that capacity, sensor hubs will intermittently switch on their sensors and transmitters, sense the earth and transmit the information of enthusiasm at consistent occasional time interims [7].

\subsection{Security:}


In a few applications, the correspondence among hubs is required to be secured enough in order to keep up the privacy. It is generally required while managing the military applications like front line reconnaissance, military tasks and so on.

\subsection{Interior Attacks:}

These are for the most part done due to the traded off hubs. These bargained hubs consistently try to upset or parallelize the system. In view of sort of movement performed by aggressor, it can be additionally named: Outside Attack-in which, an assailant can supplant/present new malignant hub from outside. Inside Attack-in which, an assailant can catches any hub; reconstruct it, to go about as vindictive hub.

\subsection{Outer Attacks:}

In these assaults, the aggressor hub isn't generally an approved take part of SN. Rely upon the direct of assailant hub, it could be classified as:

\subsection{Gadget Level Capability Attack:}

This class of assaults is sorted rely upon the capacity of the gadget that is being utilized for assaulting. An assailant may assault the WSN either utilizing a sensor gadget (Sensor Level) or all the more effective workstation gadget (Laptop Level). An enemy can exceedingly harm the framework on the off chance that he/she utilizes Laptop Class assault having all the more intense calculation, stockpiling and battery life. Close to the previously mentioned groupings, an assailant may use at least one of the resulting assault strategies.

\subsection{Spying:}

In which an assailant quietly tune in to media for dispatch in the midst of two gatherings and don't adjusts the information. It's an uninvolved method.

\subsection{Radio sticking:}

In this assault, the aggressor tries to upset the correspondence by sending few radio waves at the comparable recurrence bringing about impedance or crashes of bundles over system. Sticking can be discontinuous or nonstop rely upon the ideal opportunity for which arrange is kept stuck.

\section{APPLICATIONS OF WSN}

The utility of wireless sensor networks are growing day by day. The main advantage of these networks or the sensor which were the major components of these networks are the easy to operate, easy to maintain and easy to move from one location to the other locations [7][8]. These sensors can work in different situations like the extreme temperature seasons or the places where it will be more hot and more cool also. They can be placed in very hot places like the volcanoes or the land mines where coal or the gold can be retrieving the underground and also they can be stored in the very cold places such that to read the temperatures outside the environments. These devices can also be placed in places like the underwater where the data from the underwater also can be received further[9]. These sensors also play a vital role in the vehicles to work for further level of automation. Several units' data can be collected and can be processed and various decisions were being generated by the machines for further 
applications and processing. Some of the application areas where these sensors and these networks are playing a key role in the real time applications and other applications [10]. They are,

Health care applications

Environmental applications

Home appliances

Military applications

\subsection{Healthcare applications}

Now a days, the usage of sensors and wireless sensor networks in health and its related issues are growing very fast. These devices can also be placed in places like the underwater where the data from the underwater also can be received further. These sensors also play a vital role in the vehicles to work for further level of automation. Several units' data can be collected and can be processed and various decisions were being generated by the machines for further applications and processing. Some of the application areas where these sensors and these networks are playing a key role in the real time applications and other applications. The concept of "eHealth" was growing faster day by day and more number of doctors is being using it.

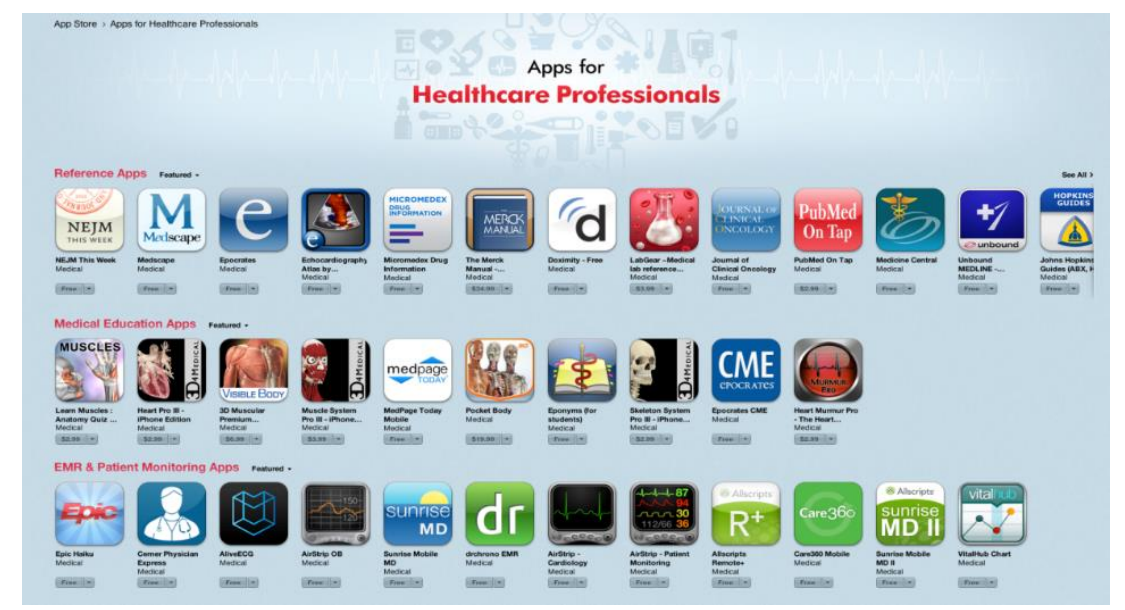

Figure.3 Medical applications example launched by Apple[6]

The application like the telemedicine was also getting more familiar and more famous for usage and is being used by more number of doctors from India and other countries also. The usage of telemedicine had increased the collaboration of various doctors from various locations in to a single channel and can collaboratively conduct a common surgery or some typical surgeries. Many doctors had got success in implementing such surgeries also.

\subsection{Environmental applications}

In order to analyze the temperatures outside the house or in the cities and also to analyze and to know the temperatures, these networks the sensors are being used such that the usage can be made easier. When the temperature are at various places, it is not possible for the human to go there and collect the data, but these units can go there and can collect the data and also for the cool places also the same scenario will be repeated. 


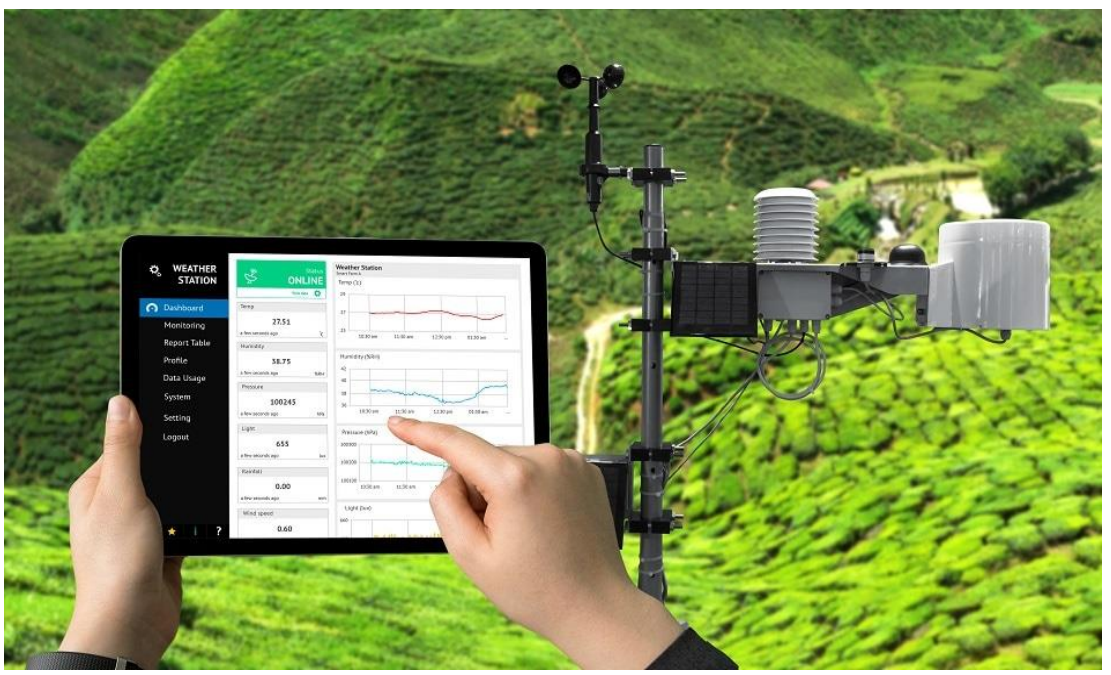

Figure.4 Environmental applications of sensor networks [7]

\subsection{Home Applications}

The other set of new and highly used wireless sensor networks are the applications those were used in various homes and how they can be used. Most of the devices used now a days are network based devices which can be controlled from anywhere by having a single internet connection between the two devices. From a single cell phone, all these devices can be controlled easily from anywhere by using an internet connection. Some of the devices that can be used wirelessly are like the AC's, Washing Machines and Owens etc.

\section{4 Military Applications}

The other important applications of these sensor networks and other wireless networks are the military applications. The utility of these sensors and their applications are growing day by day to reduce the risk of human life in military applications and devices. If a person needs to verify the status of some bombs presence or some other devices like presence of human beings and other sources, the usage of these sensors and applications can reduce the damage and also it can reduce the intervention of human beings. Sometimes the data also can be manipulated by the human being, but in practical cases where these devices are used, it is not possible for anyone to tamper or change the actual data that was found at scenarios. Hence, it is always required and increased more of using these wireless sensors and sensor networks in military and its related defense applications.

It is not always possible for the people to cross the coolest places. If we can place a sensor in such cool places, we can collect the data from those set of sensors at various intervals of time and can be analyzed at easier times.

\section{SECURITY ASPECTS OF WSN}

The fame of WSN has been enormously on a top as for various applications like environmental change, natural observing, movement checking and home robotization. In this manner keeping the WSN has dependably been a testing errand. Cryptography gives security through symmetric key procedures, hilter kilter key methods and hash work. Since WSN are exceptionally compelled as far as figuring, correspondence and battery control, it requires a 
light weight cryptographic calculation. Because of limitations of sensor hubs, the determination of cryptographic method is essential in WSN. Cryptography in WSN can be clarified in the accompanying three angles: symmetric, hilter kilter and hash work[4].

\section{SIMULATION PLATFORM IN WSN}

In WSNs, reenactment is a standout amongst the most overwhelming assessment procedures for the improvement of new correspondence structures, and system conventions and to test and approve the current one in different situations. Reproduction encourages analysts to get noteworthy data on achievability and practicability vital to the execution of the framework preceding contributing critical time and cash. In WSNs, reenactment based testing and approval has numerous favorable circumstances, for example, simplicity of execution, bring down cost, adaptability and probability of testing expansive scale systems. The accessibility of a substantial number of reproduction instruments and particular necessity (e.g. vitality imperatives, huge scale sending) of WSNs makes it troublesome for a client to pick an almost culminate apparatus for his assessment. To address this issue, overview is introduced probably the most broadly utilized and best in class reenactment devices for WSNs. The point is to enable scientists in the determination of a proper recreation to instrument to assess their work, and to obtain solid outcomes for expansive scale WSNs [5].

Table 1. Comparison of various simulation tools available

\begin{tabular}{|c|c|c|c|c|}
\hline $\begin{array}{c}\text { Features of } \\
\text { the Tools } \\
\text { available }\end{array}$ & $\begin{array}{c}\text { Interfacing } \\
\text { unit details }\end{array}$ & $\begin{array}{c}\text { User support } \\
\text { and usage }\end{array}$ & $\begin{array}{c}\text { Modules of the } \\
\text { networks available }\end{array}$ & Scalability \\
\hline OMNeT++ & $\begin{array}{c}\text { OTcL and } \\
\text { C++ with } \\
\text { less support, } \\
\text { Good GUI } \\
\text { support }\end{array}$ & $\begin{array}{c}\text { User support is } \\
\text { good and it is } \\
\text { an open source }\end{array}$ & $\begin{array}{c}\text { Availability of } \\
\text { modules and nodes are } \\
\text { excellent in actual } \\
\text { scenarios }\end{array}$ & High \\
\hline NS-2 & C++ & $\begin{array}{c}\text { User support is } \\
\text { good and it is } \\
\text { an open source }\end{array}$ & $\begin{array}{c}\text { Availability of } \\
\text { modules and nodes are } \\
\text { excellent in actual } \\
\text { scenarios }\end{array}$ & $\begin{array}{c}\text { Very } \\
\text { limited }\end{array}$ \\
\hline SESNE & $\begin{array}{c}\text { GUI support } \\
\text { is good and } \\
\text { C++ }\end{array}$ & $\begin{array}{c}\text { User support is } \\
\text { very poor }\end{array}$ & $\begin{array}{c}\text { Availability of } \\
\text { modules and nodes are } \\
\text { excellent in actual } \\
\text { scenarios }\end{array}$ & High \\
\hline OPNET & $\begin{array}{c}\text { C++, C and } \\
\text { Java }\end{array}$ & $\begin{array}{c}\text { For Academics } \\
\text { it is free and } \\
\text { for others it is } \\
\text { commercial }\end{array}$ & $\begin{array}{c}\text { Availability of } \\
\text { modules and nodes are } \\
\text { excellent in actual } \\
\text { scenarios }\end{array}$ & Normal \\
\hline TOSSIM & $\begin{array}{c}\text { GUI support } \\
\text { is good, C++ } \\
\text { and Python } \\
\text { will be } \\
\text { supported }\end{array}$ & $\begin{array}{c}\text { User support is } \\
\text { good and it is } \\
\text { an open source }\end{array}$ & $\begin{array}{c}\text { Availability of } \\
\text { modules and nodes are } \\
\text { excellent in actual } \\
\text { scenarios }\end{array}$ & High \\
\hline
\end{tabular}




\section{CONCLUSION}

WSNs have been significantly utilized as a part of different areas of human life. The detecting innovation has made it workable for any sensor hub to convey and react to the diverse qualities. This paper has informed about different viewpoints in WSN. With the concise prologue to the WSN, the extraordinary issues have been examined. Applications have been featured alongside the security angles in WSN. From that point the forbidden examination of various recreation programming has been given. It can be finished up from the examination done in this paper. WSN has altered relatively every area of present day period. It has colossal extent of research in dealing with various parts of human life.

\section{References}

[1] I.F. Akyildiz, S. Weilian, Y. Sankarasubramaniam, E.Cayirci, "A survey on sensor networks", IEEE Communications Magazine, (2002), Vol. 40, No.8, pp. 102-114. DOI: 10.1109/MCOM.2002.1024422

[2] Preetkamal Singh et. Al., "A Brief Research Study of Wireless Sensor Network", Advances in Computational Sciences and Technology, Vol.10, no.5, pp.733-739. (2017)

[3] Samira Kalantary, Sara Taghipour, "A Survey on architectures, protocols, applications and management in wireless Sensor Networks”, Journal of Advanced Computer Science \&Technology, (2014), Vol.10, No.1, pp. $1-11$.

[4] KazemSohraby, Daniel Minoli, TaiebZnati, "Wireless Sensor Networks", Wiley Publications, Second Edition, (2014). DOI: 10.1016/s1389-1286(03)00351-7

[5] Gaurav Sharma, SumanBala, Anil K. Verma, "Security Frameworks for Wireless Sensor Networks-Review," 2nd International Conference on Communication, Computing \& Security [ICCCS-2012], (2012), No. 6, pp. 978-987. DOI: 10.1016/j.protcy.2012.10.119

[6] Muhammad Zahid Khan et al., "Limitations of Simulation Tools for LargeScale Wireless Sensor Networks," Workshops of International Conference on Advanced Information Networking and Applications, (2011), pp. 820-825. DOI: 10.1109/WAINA.2011.59

[7] A Blog written by Tome Lewis on "Imedical Apps" in MEDPAGE TODAY on (2013).

[8] An article by Louis Sal on "Types of Sensors for Environmental Monitoring" at AZO sensors on November, (2018).

[9] Abdelbassat Trad, "Performance trade-offs of encryption algorithms for Wireless Sensor Networks"2014, World Congress on Computer applications and Information Systems, pp.125-135. (2014) DOI: 10.1109/WCCAIS.2014.6916625

[10] Neetu Kumari, Nikita Patel, Satyajit Anand, Partha Pratim Bhattacharya, "Designing Low Power Wireless Sensor Networks: A Brief Survey”, International Journal of Advanced Research in Electrical, Electronics and Instrumentation Engineering, Vol.2, No.9, (2013), pp.4447-4456. 